\title{
Senior Editor Appointments: Augustus Way Fountain III and Jessica DeGroote Nelson
}

\author{
Adam Wax \\ Editor-in-Chief
}

The role of senior editor is an important one at Optical Engineering. Since our journal covers such a broad array of topics, we rely on our senior editors to bring a high level of expertise in their specialty area. This ensures that submitted papers are initially evaluated with greater knowledge of the field and can find their way to the right associate editors and in turn the right peer reviewers. It is with great enthusiasm that I would like to introduce our two newest senior editors: Dr. Augustus Way Fountain III and Dr. Jessica DeGroote Nelson, who were among our most experienced and accomplished editorial board members.

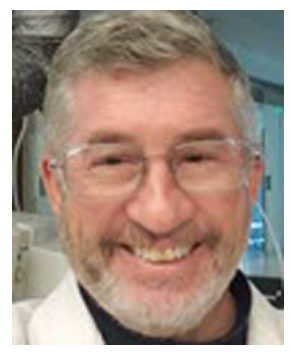

Dr. Augustus Way Fountain III teaches chemistry within the Honors College at the University of South Carolina. He recently retired and moved to Columbia, South Carolina, after 35 years of military and civilian service with the U.S. Army. Prior to teaching at U of SC, he served in a range of positions, including deputy chief scientist for the U.S. Army. He is an internationally recognized expert in electro-optics as it pertains to chemical, biological, radiological, nuclear, and explosives (CBRNE) sensing. As a military officer, Fountain served with the $1^{\text {st }}$ Ranger Battalion in Operation Just Cause, the $82^{\text {nd }}$ Airborne Division during Operations Desert Shield and Desert Storm, and as a professor of chemistry at the United States Military Academy. In 2016, he was honored with a Meritorious Senior Professional Presidential Rank Award, and in 2014 he was elected as a Fellow of SPIE.

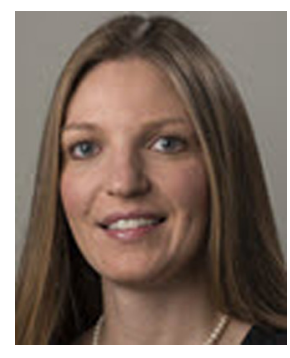

Dr. Jessica DeGroote Nelson is the director of technology and strategy at Optimax Systems, Inc., a high-precision optics manufacturer located in Ontario, New York. She joined the company in 2007 after graduation from The Institute of Optics at the University of Rochester with a BS, MS, and PhD in optics. She furthered her education with an Executive MBA degree from the Simon School of Business at the University of Rochester in 2013. Jessica is a fellow member of SPIE and serves as the editor the SPIE Press Tutorial Text Book Series in addition to her role at Optical Engineering. She is also an adjunct faculty member at The Institute of Optics at the University of Rochester.

() 2022 Society of Photo-Optical Instrumentation Engineers (SPIE) 